\title{
Estudos sobre mostras científicas: levantamento de trabalhos apresentados em eventos da área de ciências
}

\author{
Studies on scientific shows: survey of papers presented in events in \\ the science area
}

Estudios sobre espectáculos científicos: encuesta de papeles presentados en eventos del área de ciencias

Guilherme Molinari Saccoㅜ; Monica Abrantes Galindo²; Ana Maria Klein ${ }^{3}$

\begin{abstract}
RESUMO
O presente estudo tem por objetivo levantar e classificar as produções científicas voltadas às feiras e mostras cientificas registradas em anais de seis edições de três eventos nacionais: ENPEC (2017 e 2019), SNEF (2017 e 2019) e EPEF (2016 e 2018). Para tanto, utilizou-se como fonte de dados os anais de cada uma das edições disponibilizadas nos sites dos eventos. Foram levantados 31 trabalhos que foram classificados a partir das instituições dos pesquisadores, nível de ensino, foco da discussão (estudante, professor, evento). Os resultados demonstram que em relação ao total de trabalhos apresentados, apenas $1 \%$ voltaram-se à temática de feiras e mostras cientificas. A maior parte das produções são de instituições públicas da região sudeste. $\mathrm{O}$ foco dos trabalhos, em sua grande maioria, volta-se para os estudantes e questões relacionadas à aprendizagem e protagonismo. Conclui-se que este campo de pesquisa pode ser mais explorado dada a relevância de feiras e mostras cientificas para a aprendizagem de ciências, bem como para a socialização dos conhecimentos científicos.
\end{abstract}

Palavras-chave: Feiras de ciências; Mostras de Ciências; Exposição de Ciências; Ciências na educação básica.

\begin{abstract}
This study aims to survey and classify scientific productions aimed at fairs and scientific exhibitions registered in the annals of six editions of three national events: ENPEC (2017 and 2019), SNEF (2017 and 2019) and EPEF (2016 and 2018). For this purpose, the annals of each of the editions made available on the event websites were used as a data source. 31 papers were collected and classified according to the researchers' institutions, level of education, focus of the discussion (student, teacher, event). The results show that in relation to the total of works presented, only 1\% turned to the theme of scientific fairs and exhibitions. Most of the productions are from public institutions in the southeastern region. Most works focus on students and issues related to
\end{abstract}

\footnotetext{
${ }^{1}$ Graduado em Física e estudante Física Biológica na Universidade Estadual Paulista Júlio de Mesquita Filho (UNESP) - São José do Rio Preto. E-mail: gui.sacco@gmail.com

${ }^{2}$ Licenciada em Física, Mestre em Ensino de Ciências e Doutora em Educação. Professora Assistente da Universidade Estadual Paulista Júlio de Mesquita Filho (UNESP) - São José do Rio Preto e colaboradora do Programa de Pós-graduação Strictu Sensu de Biociências (UNESP - São José do Rio Preto). E-mail: monica.galindo@unesp.br

${ }^{3}$ Graduada em Pedagogia e em Ciências Sociais e Mestre e Doutora em Educação. Professora da Universidade Estadual Paulista (UNESP) campus São José do Rio Preto e do Programa Multidisciplinar Interunidades de Pós-graduação Strictu Sensu: Ensino e Processos Formativos (UNESP São José do Rio Preto/Ilha Solteira e Jaboticabal). E-mail: ana.klein@unesp.br
} 
learning and leadership. It is concluded that this field of research can be further explored given the relevance of fairs and scientific exhibitions for science learning, as well as for the socialization of scientific knowledge.

Keywords: Science fairs; Science Exhibits; Science exhibition; Science in basic education.

\section{RESUMEN}

Este estudio tiene como objetivo relevar y clasificar las producciones científicas destinadas a ferias $y$ exposiciones cientificas inscritas en los anales de seis ediciones de tres eventos nacionales: ENPEC (2017 y 2019), SNEF (2017 y 2019) y EPEF (2016 y 2018). Para ello, se utilizaron como fuente de datos los anales de cada una de las ediciones puestas a disposición en los sitios web del evento. Se recolectaron y clasificaron 31 artículos de acuerdo a las instituciones de los investigadores, nivel de educación, foco de discusión (alumno, docente, evento). Los resultados muestran que en relación al total de trabajos presentados, solo el 1\% se volcó hacia el tema de ferias y exposiciones científicas. La mayoría de las producciones son de instituciones públicas de la región sureste. La mayoría de los trabajos se enfocan en estudiantes y temas relacionados con el aprendizaje y el liderazgo. Se concluye que este campo de investigación se puede profundizar dada la relevancia de las ferias y exposiciones científicas para el aprendizaje de las ciencias, así como para la socialización del conocimiento.

Palabras clave: Ferias de ciencia; Exposiciones científicas; Exposición de ciencia, La ciencia en la educación básica.

\section{INTRODUÇÃO}

Feiras de ciências, exposições e mostras científicas são oportunidades ou espaços para que o produto dos projetos de pesquisa ou demonstrações realizadas pelos estudantes e seus professores orientadores sejam apresentados, compartilhando dessa forma, conhecimentos entre os grupos e os diferentes públicos visitantes desses espaços. Por meio de documentos oficiais como as Diretrizes Curriculares Nacionais para a Educação Básica (DCNEB) (BRASIL, 2013) e a Base Nacional Comum Curricular (BNCC) (BRASIL, 2017) a divulgação científica e a pesquisa como princípio educativo têm espaço nas escolas brasileiras, pelo menos em termos de documentos oficiais, e assim, de alguma maneira buscando favorecer a produção de conhecimento. As Diretrizes recomendam 0 desenvolvimento da capacidade de pesquisa como importante para que os estudantes envolvidos "busquem e (re) construam conhecimentos" (BRASIL, 2013, p. 164).

Um aspecto fundamental à pesquisa como princípio educativo é que os trabalhos devem ser produzidos pelos estudantes e posteriormente passem pelo processo de comunicação (GONÇALVES, 2011). Assim, é necessário que tanto o professor quanto o estudante se mobilizem para a produção de conhecimentos por meio da pesquisa. Os conteúdos previstos nos currículos exigem dos professores uma mudança de comportamento frente ao desconhecido: passam de transmissores de conhecimento para o papel de mediador, aprendendo juntamente com os estudantes e buscando caminhos para essas novas aprendizagens.

Neste sentido, as feiras de ciências, bem como mostras de ciências ou exposições de ciências, se mostram como movimentos importantes para a pesquisa e a divulgação científica, contribuindo de forma significativa na formação dos participantes de uma forma geral - estudantes, professores e público visitante. São movimentos consolidados no país, com início na década de 60 (MANCUSO; LEITE FILHO, 2006) ocorrendo em ambientes escolares e espaços não-formais, nos âmbitos municipal, estadual e nacional. De acordo com Mancuso e Leite Filho (2006), a palavra ciências, ocasionalmente é confundida com as ciências do currículo escolar, quando, na realidade, deveria ser 
compreendida "no seu sentido mais amplo, referindo-se muito mais à 'pesquisa científica com qualquer ciência', o que pode (e deve) ocorrer em todos os campos do conhecimento" (MANCUSO; LEITE FILHO, 2006, p. 17). Para Neves e Gonçalves (1989), as feiras de ciências consistem na apresentação de trabalhos e na relação expositor-visitante, na qual são apresentados materiais, objetivos, metodologia utilizada, resultados e conclusões obtidas. Portanto, estes eventos científicos têm como finalidade criar diferentes espaços para diálogos, discussões e debates como: sessões de pôsteres, comunicações orais, mesas redondas e palestras, onde os autores e visitantes podem interagir, trocar conhecimentos e assim sendo, a ciência pode ser divulgada e debatida, alcançando o maior número de pessoas possível.

Temos dados de pesquisa que nos sugerem que a crença e confiança no conhecimento científico e nas instituições que produzem esse conhecimento é preponderante atualmente (DE NEGRI; FERNANDEZ; ALVES, 2019). Causa espanto, entretanto que ideias como a teoria da terra plana ou a dúvida sobre o fenômeno do aquecimento global, assim como o movimento anti-vacinas tenham se torando objeto de debate mais frequente. Esse aumento do debate não significa necessariamente que mais pessoas passaram a acreditar nesse tipo de teoria, entretanto revela a relevância e a necessidade crescente da divulgação cientifica de maneiras diversas para o conjunto da população.

O objetivo deste artigo é apresentar um estudo bibliométrico referente às palavras chaves: feiras de ciências, mostras de ciências e exposições de ciências nos trabalhos apresentados em eventos científicos nacionais do ano de 2016 até 2019. Os eventos selecionados para esta pesquisa são: ENPEC (Encontro Nacional de Pesquisa e Ensino de Física) - 2017 e 2019, SNEF (Simpósio Nacional de Ensino de Física) - 2017 e 2019 e EPEF (Encontro de Pesquisa e Ensino de Física) - 2016 e 2018.

\section{METODOLOGIA}

O intuito do presente trabalho é quantificar e classificar a produção científica registrada em anais de seis edições de três eventos científicos nacionais: ENPEC (2017 e 2019), SNEF (2017 e 2019) e EPEF (2016 e 2018). Para tanto, utilizou-se como fonte de dados os anais com os artigos completos de cada uma das edições disponibilizadas nos sites dos eventos. Em seguida, procedeu-se a uma busca nos documentos, utilizando-se como descritores: feiras de ciências, mostras de ciências e exposições de ciências nos campos de palavra-chave, resumo e títulos das produções. Após a identificação dos trabalhos passou-se à classificação dos mesmos utilizando como critérios: nível de ensino, localização da instituição (região) e seu foco. Os trabalhos foram categorizados a partir de seu conteúdo, buscando o foco do estudo desenvolvido. As três categorias de análise foram: foco centrado nos estudantes, foco centrado nos professores e foco centrado nos eventos. Estes focos possibilitam a compreensão sobre qual a perspectiva dos trabalhos, aprendizagem (foco no aluno); ensino (foco no professor e na sua formação) e socialização dos conhecimentos científicos (foco no evento).

\subsection{As pesquisas intituladas do tipo "estudo bibliométrico"}

O surgimento dos estudos bibliométricos no Brasil se deu na década de 1970 tendo como principal contribuinte para seu desenvolvimento o Instituto Brasileiro de Bibliografia e Documentação, IBBD, hoje Instituto Brasileiro de Informação Científica e Tecnológica, IBICT (ARAÚJO, 2006). A bibliometria é uma técnica quantitativa e estatística que tem como finalidade medir os índices de produção e disseminação do conhecimento científico (ARAÚjO, 2006). 
Para Potter (1981) a bibliometria pode ser definida como uma forma de medir padrões de comunicação escrita, assim como, dos autores dessas comunicações. Outra definição é que se trata de um conjunto de técnicas cujo objetivo é quantificar o processo de comunicação escrita. Técnicas de bibliometria vem sendo usadas, principalmente, para identificar autores mais produtivos, para encontrar paradigmas na ciência e na identificação de periódicos mais produtivos. (IKPAAHINDLI, 1985).

Segundo Araújo (2006), um dos focos da bibliometria, desde os primeiros estudos, se concentra em analisar a produção científica existente sobre determinados assuntos.

Esse tipo de estudo tem se popularizado entre os acadêmicos em função da grande quantidade de material bibliográfico que é produzido e disponibilizado atualmente. Ter uma visão resumida e sistematizada disso pode facilitar o entendimento e até mesmo apontar futuros caminhos de pesquisa. Os resultados de um estudo bibliométrico podem também auxiliar jovens pesquisadores ou mesmo aqueles mais experientes que deparam com uma nova temática.

Nesse sentido, diante da potencialidade das feiras e mostras de ciências para a divulgação do conhecimento científico, nosso interesse em ter uma visão resumida e sistematizada da maneira como elas têm sido apresentadas em eventos científicos.

\subsection{Sobre os encontros: EPEF, ENPEC E SNEF}

Ocorrido em Natal - RN, na Universidade Federal do Rio Grande do Norte, o EPEF 2016 (Encontro de Pesquisa e Ensino de Física), tem como objetivo desempenhar um papel seminal na promoção da pesquisa científica no país, assumindo sempre uma posição independente e construtivamente crítica nos grandes assuntos que dominaram o cenário científico e tecnológico brasileiro. Esta edição de 2016, foi uma edição especial dos eventos oficiais da SBF (Sociedade Brasileira de Física), reunindo todas suas áreas de atuação, em comemoração a seu cinquentenário e também para estimular a colaboração entre pesquisadores de diferentes áreas. (EPEF, 2016).

O EPEF 2018 aconteceu em Campos do Jordão - SP, com a temática "Os desafios da pesquisa em Ensino de Física frente às tensões contemporâneas". O encontro, segundo os organizadores, tem se mostrado um espaço privilegiado para a discussão entre pesquisadores de diferentes regiões, promovendo reflexões e ações de cunho político-científico-educacional e propiciando a formação de pesquisadores em ensino de Física. O encontro contou com diferentes espaços para diálogos, discussões e debates como: sessões de pôsteres, comunicações orais, mesas redondas e palestras (EPEF, 2018).

O ENPEC (Encontro Nacional de Pesquisa em Educação em Ciências) é um evento também bienal promovido pela Associação Brasileira de Pesquisa em Educação em Ciências (ABRAPEC) e tem como objetivo reunir e favorecer a interação entre os pesquisadores da área de Ensino de Física, de Biologia, de Química, de Geociências, de Ambiente, de Saúde e áreas afins, com finalidade de discutir trabalhos de pesquisa recentes e tratar de temas de interesse da ABRAPEC. O público deste encontro é formado por interessados na pesquisa em Educação em Ciências da Natureza, da Saúde e do Ambiente, incluindo professores-pesquisadores da Educação Básica e Superior, estudantes de pós-graduação, estudantes de licenciatura, formadores de professores e pesquisadores. O evento de 2017 aconteceu em Florianópolis - SC. (ENPEC, 2017). 
O ENPEC de 2019, ocorrido em Natal - RN, teve como tema "Pesquisa em Educação em Ciências: Diferença, Justiça Social e Democracia", com a intenção de ampliar a oportunidade de fomentar novos diálogos, valorizando espaços acadêmicos públicos e culturais. O público-alvo do XII ENPEC é formado por interessados na pesquisa em Educação em Ciências da Natureza e áreas correlatas, incluindo professores-pesquisadores da Educação Básica e Superior, estudantes de pós-graduação, estudantes de licenciatura, formadores de professores e pesquisadores. (ENPEC, 2019).

O SNEF 2017 (Simpósio Nacional de Ensino de Física) ocorrido em São Carlos - SP, no Instituto de Física da USP, tinha como proposta o tema "A Física e o Cidadão Contemporâneo". Buscando um olhar para o conhecimento físico que se reconheça e valorize como um conhecimento capaz de contribuir com o potencial que todos têm de ser e estar no mundo de forma crítica, participativa, empenhando-se na construção coletiva do bem comum e de um mundo melhor. De certo modo, os Simpósios Nacionais de Ensino de Física têm se constituído como um espaço privilegiado de troca de experiências, análises e discussões sobre o ensino de Física para diferentes públicos e em diferentes espaços formativos (SNEF, 2017).

O SNEF 2019 aconteceu em Salvador - BA, no Instituto Federal de Educação, Ciência e Tecnologia da Bahia em parceria com a Universidade Federal da Bahia, tendo como tema proposto para esta edição, "O Ensino de Física no século XXI: Caminhos para uma educação inclusiva". A partir do tema proposto para o Simpósio, o intuito seria convidar a comunidade de estudantes, docentes, pesquisadoras e pesquisadores de Física, de todos os níveis de ensino, para submeterem propostas de cursos, oficinas, mostras, encontros, exposições e outras atividades, principalmente, considerando como podemos tornar o Ensino de Física um espaço mais inclusivo (SNEF, 2019).

Estes eventos foram escolhidos devido à importância de suas produções, ao elevado número de participantes e ao alto nível de disseminação da ciência envolvido. Além disto, são grandes eventos nacionais, e que abrangem muitas áreas do conhecimento, das ciências em geral e do ensino e aprendizagem.

\section{DISCUSSÕES E RESULTADOS}

\subsection{Número total de trabalhos apresentados nos eventos}

Feita a pesquisa e filtragem das palavras-chaves dos trabalhos dos eventos científicos em duas edições dos encontros, percebe-se que o ENPEC (Encontro Nacional de Pesquisa em Educação em Ciências) possui a maior concentração de trabalhos apresentados (15), seja em forma de comunicação oral ou painéis ou pôsteres. Em segundo lugar está o SNEF (Simpósio Nacional de Ensino de Física) somando 13 trabalhos, que continham as palavras-chaves pesquisadas. Já o EPEF (Encontro de Pesquisa e Ensino de Física) em dois eventos, somou três trabalhos apresentados com os temas abordados no presente trabalho.

Destaca-se o ano de 2017 com o maior número de trabalhos apresentados (19) nestes eventos. Em seguida o ano de 2019 com nove trabalhos. Em 2018 com dois trabalhos apresentados, e por fim 2016 com apenas um trabalho contendo os assuntos relativos às palavras chaves selecionadas para esta pesquisa. 
Gráfico 1: Número total de trabalhos apresentados nos eventos científicos.

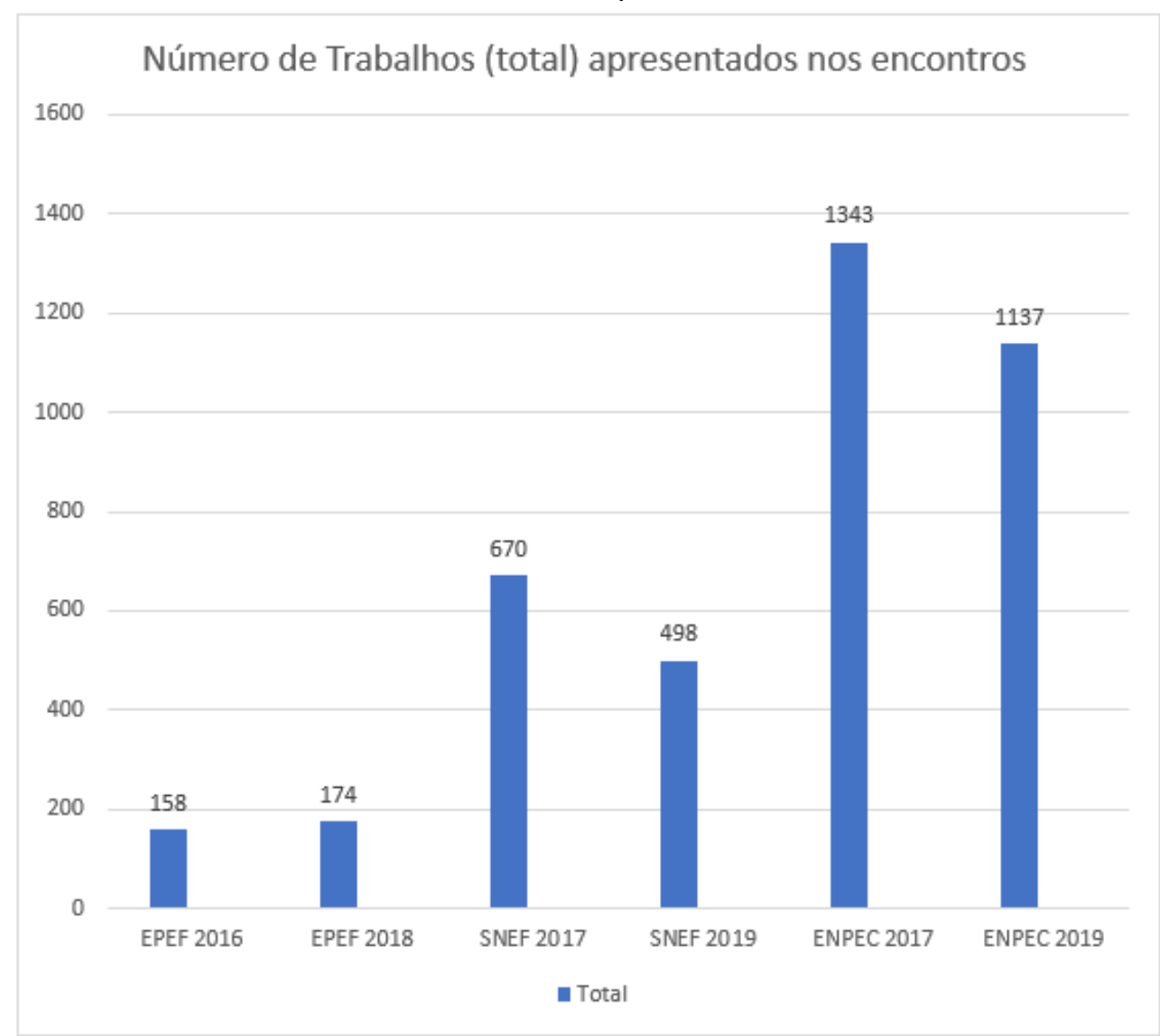

Fonte: elaborado pelo autor

Gráfico 2 - Número de trabalhos apresentados por evento com foco em feiras de ciências

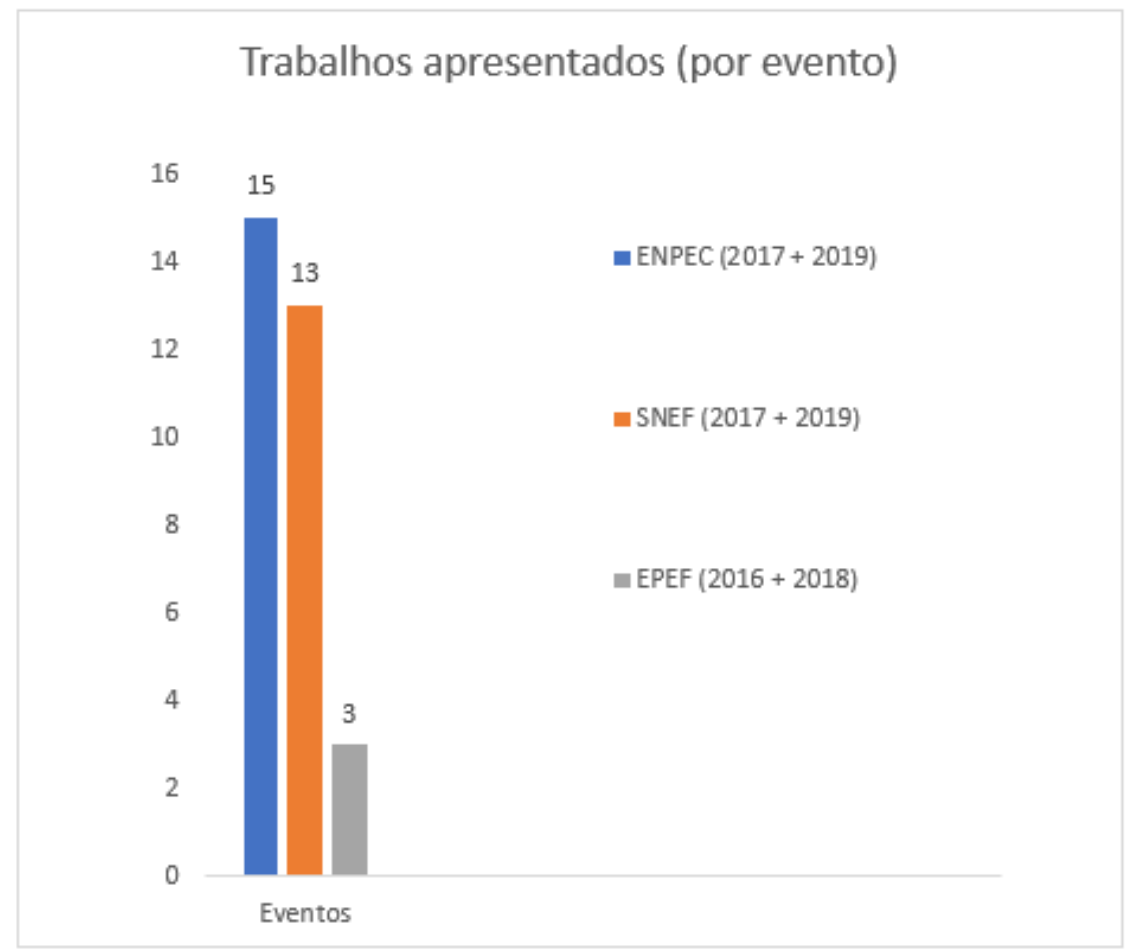

Fonte: Elaborado pelo autor

Após a pesquisa a respeito dos trabalhos apresentados, fizemos a separação pelas linhas de pesquisa nas quais os trabalhos foram apresentados nos respectivos eventos, conforme a tabela 1. 
Tabela 1 - Linhas de Pesquisa dos eventos nas quais os trabalhos selecionados foram apresentados

Comunicação em práticas educativas formais, informais e nãoformais e o ensino de Física

1

Ensino, aprendizagem e avaliação em física / Tecnologias da informação e comunicação e o ensino de Física

Ensino / Aprendizagem / Avaliação em Física

Abordagem CTSA e o Ensino de Física

Educação científica, Política e Sociedade

Educação ambiental e Educação em ciências

História, Filosofia e Sociologia da ciência na educação em ciências

Alfabetização científica e tecnológica, Abordagens CTS e CTSA e educação em ciências

Educação em espaços não-formais e divulgação científica

Divulgação científica e educação não formal

Divulgação científica, educação não formal e informal

Ensino e aprendizagem em física

Materiais, métodos e estratégias de ensino de física
1

2

1

1

1

1

1

12

5

1

2

2

Dentre as linhas de pesquisa destaca-se a de "Educação em espaços não-formais e divulgação científica", que possui o maior número de trabalhos apresentados (12) nestes eventos. Em seguida, a categoria "Divulgação científica e educação não formal" com cinco trabalhos.

\subsection{Quantidade de trabalhos por evento (ENPEC, SNEF E EPEF (2016-2019)}

A partir do gráfico 1, que mostra o número total de trabalhos apresentados nos encontros: EPEF 2016 (158), EPEF 2018 (174), SNEF 2017 (670), SNEF 2019 (498), ENPEC 2017 (1343) e ENPEC 2019 (1137). Obtemos a tabela 2 abaixo, que mostra a porcentagem de trabalhos que utilizaram as palavras-chaves destacadas para este estudo.

Tabela 2: Porcentagem do número total de trabalhos referente às feiras de ciências

\begin{tabular}{ccccc} 
Evento & Ano & $\begin{array}{c}\text { Total de trabalhos } \\
\text { apresentados }\end{array}$ & $\begin{array}{c}\text { Trabalhos } \\
\text { relacionados às } \\
\text { feiras de ciências }\end{array}$ & $\begin{array}{c}\text { Porcentagem de } \\
\text { trabalhos relacionados } \\
\text { as feiras de ciências } \\
\text { em relação ao total }\end{array}$ \\
\hline EPEF & 2016 & 158 & 1 & $0.63 \%$ \\
\hline EPEF & 2018 & 174 & 2 & $1.15 \%$ \\
\hline SNEF & 2017 & 670 & 8 & $1.34 \%$ \\
\hline SNEF & 2019 & 498 & 5 & $1.20 \%$ \\
\hline ENPEC & 2017 & 1.343 & 10 & $0.74 \%$ \\
\hline ENPEC & 2019 & 1.137 & 5 & $0.44 \%$ \\
\hline
\end{tabular}

Fonte: elaborado pelo autor 
Gráfico 3 - Total de trabalhos, com o tema feira de ciências, apresentados nos eventos científicos.

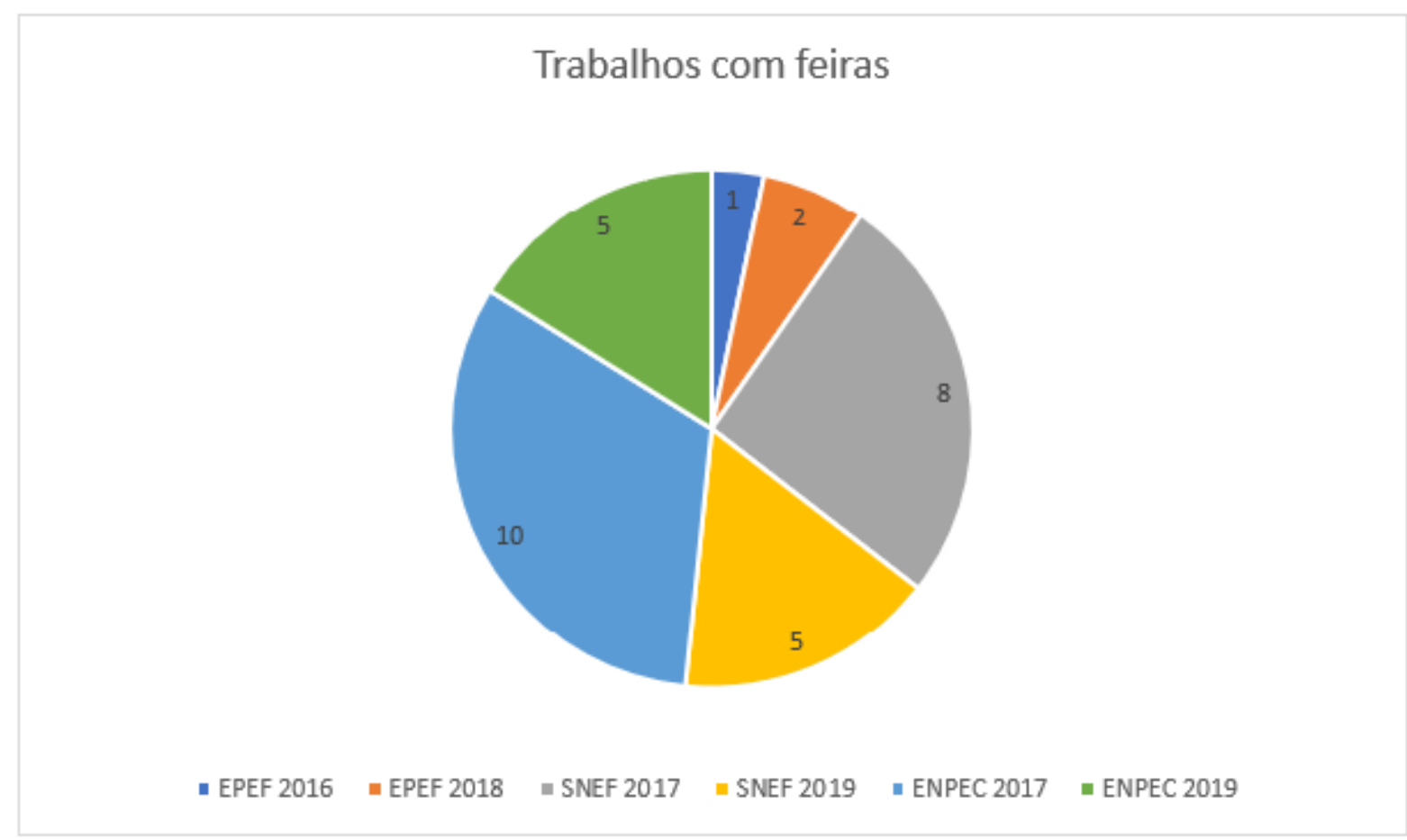

Fonte: elaborado pelo autor

De acordo com a tabela 2, que mostra o número de trabalhos total apresentados nos eventos e também a porcentagem dos trabalhos envolvidos com feiras de ciências, podemos perceber a diferença entre as produções científicas nos eventos estudados. Destacando-se o ENPEC, que soma, em dois anais, um total de 15 trabalhos envolvendo o estudo das feiras científicas.

\subsection{Representatividade de cada região do país nos encontros}

Após feita a busca e a seleção de trabalhos apresentados nos eventos por palavras-chaves, títulos e resumos, categorizou-se de acordo com as instituições dos autores principais e a distribuição regional vislumbrando a distribuição da produção no país.

Tabela 3 - Trabalhos apresentados por região do Brasil.

\section{Região}

\section{Número de Instituições de ensino superior}

Número de Trabalhos apresentados

(entre os anos de 2016 e 2019 no ENPEC, SNEF e EPEF)

\begin{tabular}{ccc}
\hline Centro-Oeste & 3 & 2 \\
\hline Nordeste & 3 & 3 \\
\hline Norte & 5 & 5 \\
\hline Sul & 6 & 9 \\
\hline Sudeste & 11 & 12 \\
\hline
\end{tabular}

Fonte: Elaborado pelo autor

Apontamos a participação de 28 Instituições de Ensino Superior, uma instituição de Ensino Médio e duas outras instituições: Secretaria de Estado da Educação (SEDUC) e da Sociedade Brasileira de Física (SBF) conforme detalharemos a seguir. 


\subsubsection{Região Centro-oeste}

Quadro 1 - Instituições do Centro-Oeste que apresentaram seus trabalhos nos eventos

\begin{tabular}{|l|c|c|c|}
\hline Instituição & $\mathbf{N}^{\circ}$ de trabalhos & $\begin{array}{c}\text { Nível de } \\
\text { ensino }\end{array}$ & Estadual/particular/federal \\
\hline $\begin{array}{l}\text { Pontifícia Universidade Católica de } \\
\text { Goiás, Escola de Ciências Exatas e } \\
\text { da Computação }{ }^{1} \text {, } \\
\text { Universidade Paulista, Instituto de }\end{array}$ & 1 & $\begin{array}{l}\text { Superior }{ }^{1} \\
\text { Superior }^{2}\end{array}$ & Privado $^{1}$ \\
$\begin{array}{l}\text { Ciências Exatas e Tecnologia } \\
\text { Campus I 2 }\end{array}$ & 1 & Superior & \\
\hline $\begin{array}{l}\text { UNEMAT - Universidade do Estado } \\
\text { do Mato Grosso/ SEDUC-Secretaria } \\
\text { de Estado de Educação do Mato } \\
\text { Grosso }\end{array}$ & 1 & Estadual \\
\hline
\end{tabular}

Fonte: Elaborado pelo autor

Na região Centro-Oeste, destacam-se três instituições de nível superior que apresentaram trabalhos nos eventos em destaque. Esta região foi representada por dois trabalhos. Um dos trabalhos contou com a participação da Secretaria de Estado de Educação do Mato Grosso - SEDUC. Dentre as três instituições da região Centro-Oeste que apresentaram os trabalhos nos eventos, nota-se que as três são de nível de ensino Superior, sendo uma instituição privada e duas instituições estaduais.

\subsubsection{Região Nordeste}

Quadro 2 - Instituições do Nordeste que apresentaram seus trabalhos nos eventos

\begin{tabular}{|l|c|c|c|}
\hline Instituição & $\begin{array}{c}\mathbf{N}^{\circ} \text { de } \\
\text { trabalhos }\end{array}$ & $\begin{array}{c}\text { Nível de } \\
\text { ensino }\end{array}$ & Estadual/particular/federal \\
\hline $\begin{array}{l}\text { Universidade Estadual do } \\
\text { Sudoeste da Bahia/Sociedade } \\
\text { Brasileira de Física }\end{array}$ & 1 & Superior & Estadual \\
\hline $\begin{array}{l}\text { UFBA - Universidade Federal da } \\
\text { Bahia }\end{array}$ & 1 & Superior & Federal \\
\hline $\begin{array}{l}\text { UFAL - Universidade Federal de } \\
\text { Alagoas }\end{array}$ & 1 & Superior & Federal \\
\hline
\end{tabular}

Fonte: Elaborado pelo autor

Na região Nordeste, destacam-se três instituições de nível superior que apresentaram trabalhos nos eventos em destaque. Esta região foi representada por três trabalhos apresentados. Um dos trabalhos contou com a participação da Sociedade Brasileira de Física - SBF. Dentre as três instituições da região Nordeste que apresentaram os trabalhos nos eventos, nota-se que as três são de nível de ensino Superior, sendo uma instituição estadual e duas instituições federais. 


\subsubsection{Região Norte}

Quadro 3 - Instituições do Norte que apresentaram seus trabalhos nos eventos

\begin{tabular}{|l|c|c|c|}
\hline Instituição & $\begin{array}{c}\mathbf{N}^{\circ} \text { de } \\
\text { trabalhos }\end{array}$ & $\begin{array}{c}\text { Nível de } \\
\text { ensino }\end{array}$ & Estadual/particular/federal \\
\hline $\begin{array}{l}\text { Instituto Federal de Educação, } \\
\text { Ciência e Tecnologia do Pará1; } \\
\text { Universidade Federal do Pará2 }\end{array}$ & 1 & $\begin{array}{c}\text { Superior }{ }^{1} \\
\text { Superior }^{2}\end{array}$ & $\begin{array}{l}\text { Federal }^{1} \\
\text { Federal }^{2}\end{array}$ \\
\hline $\begin{array}{l}\text { Universidade Federal de Sergipe - } \\
\text { Campus Prof. Alberto Carvalho }\end{array}$ & 1 & Superior & Federal \\
\hline Universidade Federal de Rondônia & 1 & Superior & Federal \\
\hline $\begin{array}{l}\text { UERR - Universidade Estadual de } \\
\text { Roraima }\end{array}$ & 2 & Superior & Estadual \\
\hline
\end{tabular}

Fonte: Elaborado pelo autor

Na região Norte, destacam-se cinco instituições de nível superior que apresentaram trabalhos nos eventos em destaque. Alguns trabalhos contaram com a participação de mais de uma instituição (parcerias) para a realização dos trabalhos apresentados. Esta região foi representada por cinco trabalhos. Dentre as cinco instituições da região Norte que apresentaram os trabalhos nos eventos, nota-se que as cinco são de nível de ensino Superior, sendo uma instituição estadual e quatro instituições federais.

\subsubsection{Região Sul}

Quadro 4 - Instituições do Sul que apresentaram seus trabalhos nos eventos

\begin{tabular}{|l|c|c|c|}
\hline Instituição & $\begin{array}{c}\mathbf{N}^{\circ} \text { de } \\
\text { trabalhos }\end{array}$ & $\begin{array}{c}\text { Nível de } \\
\text { ensino }\end{array}$ & Estadual/particular/federal \\
\hline UFPR - Universidade Federal do Paraná & 1 & Superior & Federal \\
\hline $\begin{array}{l}\text { ULBRA - Universidade Luterana do } \\
\text { Brasil }\end{array}$ & 1 & Superior & Privado \\
\hline UNIVATES/CETEC & 3 & Superior & Privado \\
\hline $\begin{array}{l}\text { PUCRS - Pontifícia Universidade } \\
\text { Católica do Rio Grande do Sul }{ }^{1} ; \\
\begin{array}{l}\text { UFMG - Universidade Federal de Minas } \\
\text { Gerais² }\end{array}\end{array}$ & 3 & $\begin{array}{l}\text { Superior }{ }^{1} \\
\text { Superior }{ }^{2}\end{array}$ & Federal $^{2}$ \\
\hline $\begin{array}{l}\text { Instituto Federal de Educação Ciência e } \\
\text { Tecnologia Farroupilha - Campus São } \\
\text { Borja }\end{array}$ & 1 & Superior & Federal \\
\hline
\end{tabular}

Fonte: Elaborado pelo autor

Na região Sul, destacam-se seis instituições de nível superior que apresentaram trabalhos nos eventos em destaque. Alguns trabalhos contaram com a participação de mais de uma instituição (parcerias) para a realização dos trabalhos apresentados. Esta região foi representada por nove trabalhos. Dentre as seis instituições da região Sul que apresentaram os trabalhos nos eventos, nota-se que as seis são de nível de ensino Superior, sendo três instituições privadas e três instituições federais. 


\subsubsection{Região Sudeste}

Quadro 5 - Instituições do Sudeste que apresentaram seus trabalhos nos eventos

\begin{tabular}{|c|c|c|c|}
\hline Instituição & $\begin{array}{c}N^{\circ} \text { de } \\
\text { trabalhos }\end{array}$ & Nível de ensino & Estadual/particular/federal \\
\hline $\begin{array}{l}\text { IFES - Instituto Federal do } \\
\text { Espírito Santo }{ }^{1} \\
\text { CEFOR - Centro de } \\
\text { Referência em Formação e } \\
\text { em Educação a Distância }{ }^{2}\end{array}$ & 1 & $\begin{array}{l}\text { Superior }^{1} \\
\text { Superior }^{2}\end{array}$ & $\begin{array}{l}\text { Federal }^{1} \\
\text { Federal }^{2}\end{array}$ \\
\hline $\begin{array}{llr}\text { UFES } & \text { - Universidade } \\
\text { Federal do Espírito Santo }\end{array}$ & 1 & Superior & Federal \\
\hline IFGW/Unicamp & 2 & Superior & Estadual \\
\hline $\begin{array}{l}\text { Instituto de Educação de } \\
\text { Minas Gerais }^{1} \text {, } \\
\text { Universidade Federal de } \\
\text { Minas Gerais/PIBID-FaE- } \\
\text { UFMG }{ }^{2}\end{array}$ & 1 & $\begin{array}{l}\text { Superior }^{1} \\
\text { Superior }^{2}\end{array}$ & $\begin{array}{l}\text { Estadual }^{1} \\
\text { Federal }^{2}\end{array}$ \\
\hline $\begin{array}{l}\text { Universidade Federal de } \\
\text { Uberlândia }\end{array}$ & 1 & Superior & Federal \\
\hline $\begin{array}{l}\text { Universidade Federal de Juiz } \\
\text { de Fora }\end{array}$ & 1 & Superior & Federal \\
\hline $\begin{array}{l}\text { Instituto Federal do Espírito } \\
\text { Santo - Campus Cariacica }\end{array}$ & 2 & Superior & Federal \\
\hline $\begin{array}{l}\text { Universidade Federal de } \\
\text { Itajubá }\end{array}$ & 1 & Superior & Federal \\
\hline $\begin{array}{lrr}\text { Instituto } & \text { Federal } & \text { de } \\
\text { Educação, Ciência } & \text { e } \\
\text { Tecnologia do Rio de } & \text { daneiro/Campus Duque de } \\
\text { Caxias } & \end{array}$ & 1 & Superior & Federal \\
\hline $\begin{array}{l}\text { E.E.E.M. D. S. MELLO - } \\
\text { Escola Estadual de Ensino } \\
\text { Médio Dr. Silva Mello }{ }^{1}\end{array}$ & 1 & Ensino Médio & Estadual \\
\hline
\end{tabular}

Fonte: Elaborado pelo autor

Na região Sudeste, destacam-se 11 instituições de nível superior que apresentaram trabalhos nos eventos em destaque. Alguns trabalhos contaram com a participação de mais de uma instituição (parcerias) para a realização dos trabalhos apresentados. Esta região foi representada por 12 trabalhos. Dentre as 12 instituições da região Sudeste que apresentaram os trabalhos nos eventos, nota-se que 11 são de nível de ensino Superior e uma instituição de ensino de nível médio, sendo três instituições estaduais e nove instituições federais. Nota-se também nesta região a participação de uma escola estadual, sendo esta a única instituição de ensino não superior desta pesquisa. Apesar de estes eventos constituírem um público acadêmico em sua maioria, este baixo número de 
participações de escolas (ensino médio) ainda é muito baixo comparado ao número de feiras em todo o país.

Gráfico 4 - Distribuição dos trabalhos quanto as regiões do país

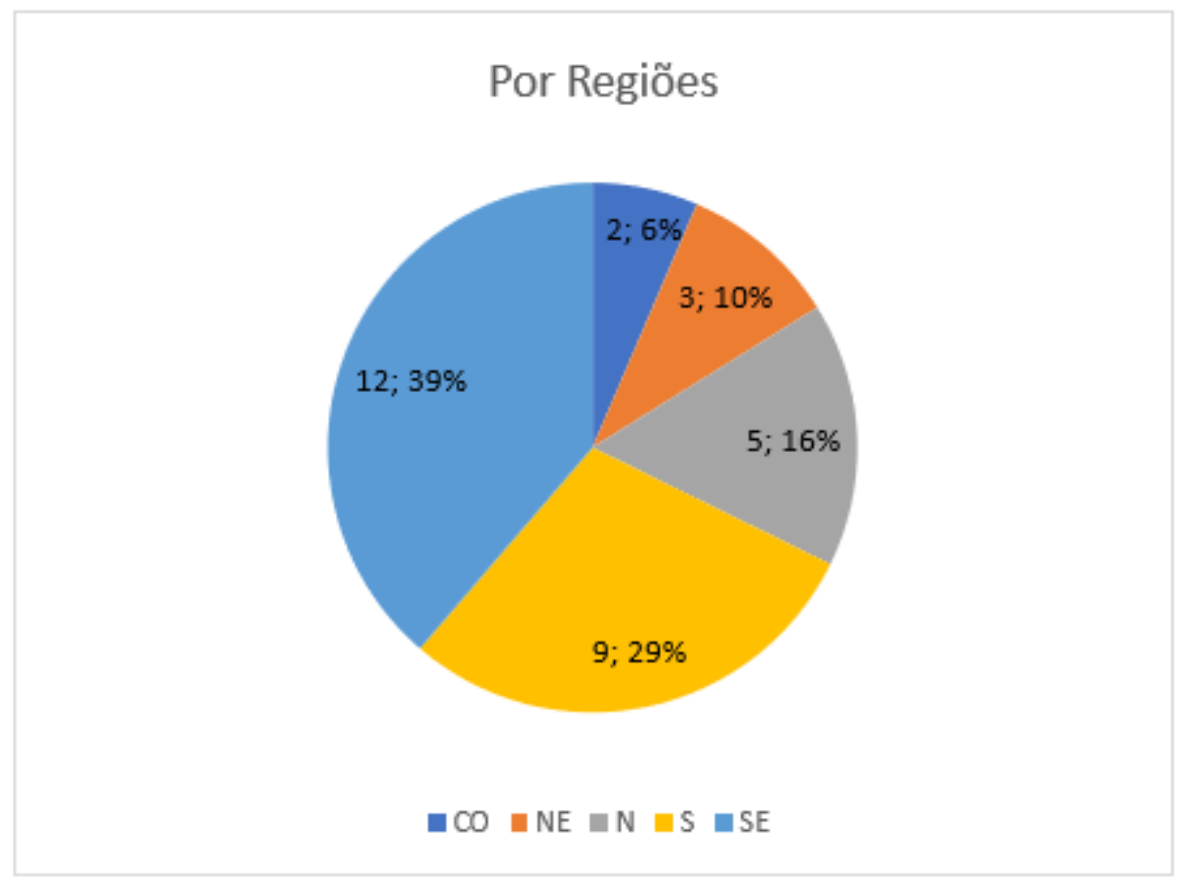

Fonte: Elaborado pelo autor

Com destaque para a região Sudeste, que apresentou maior concentração de pesquisas relacionadas às feiras de ciências, com 12 trabalhos (39\%) e 12 instituições de ensino envolvidas, seguidas pela região Sul, Norte, Nordeste e Centro-Oeste. Das 31 instituições, 19 instituições são federais, oito instituições estaduais e quatro instituições privadas.

De acordo do CWTS Leiden Ranking (2020), que é o ranking que classifica as universidades em todo o mundo por número de publicações acadêmicas de acordo com o volume e o impacto das citações das publicações nessas instituições, elaborado pelo Centro de Estudos em Ciência e Tecnologia da Universidade de Leiden, na Holanda, é possível notar, a partir do número de produções científicas das instituições mais bem colocadas, as regiões que mais produzem.

Grande parte das pesquisas realizadas no Brasil se dão em nível de pós-graduação. Segundo dados da Capes - Há no Brasil 4641 programas de pós-graduação, sendo que: 399 estão na região CentroOeste; 963 no Nordeste; 287 no Norte; 1993 no Sudeste e 999 no Sul. As instituições federais, incluindo universidades, institutos federais e fundações, são responsáveis por $58 \%$ destes cursos, $22 \%$ são ofertados por instituições estaduais ou municipais e $20 \%$ por particulares. Estes dados demonstram a importância das instituições públicas e também a maior concentração de programas de pós-graduação na região sudeste, fato que impacta na produção cientifica por região.

Outro dado refere-se à pouca participação das instituições diferentes das dedicadas ao ensino superior nas pesquisas. Apenas uma instituição de Ensino Médio e duas outras instituições: Secretaria de Estado da Educação (SEDUC) e da Sociedade Brasileira de Física (SBF), estão dentre as instituições dos autores dos 31 trabalhos encontrados. Considerando que a maioria dessas feiras são realizadas em instituições da Educação Básica ou para os alunos da Educação Básica, destacamos a pouca presença das instituições nas quais as feiras acontecem. Como já destacava Sacristán (2006), o 
discurso sobre o trabalho docente ainda é parcamente feito pelos próprios docentes e suas instituições.

\subsection{Focos das pesquisas nos trabalhos analisados}

Analisou-se nas produções os participantes envolvidos e focos das pesquisas empregados. Quanto ao foco geral dos trabalhos apresentados foi possível categorizá-los em: foco centrado nos estudantes, foco centrado nos professores e foco centrado nos eventos.

Tabela 4 - Trabalhos apresentados separados por objetivo (foco) da pesquisa.

\begin{tabular}{cc}
\hline Foco & Quantidade de trabalhos \\
\hline Estudante (básico) & 15 \\
\hline Professor & 4 \\
\hline Evento (relação feira-sociedade) & 4 \\
\hline Universitários (Superior) & 2 \\
\hline Estudante + Professor & 4 \\
\hline Estudante + Professor + Evento & 2 \\
\hline
\end{tabular}

Fonte: Elaborado pelo autor

\subsubsection{Foco centrado nos estudantes}

Neste caso, os trabalhos tinham como enfoque principal da pesquisa o estudante: estudantes visitantes da feira, estudantes como sujeito-pesquisador, a verificação da aprendizagem dos estudantes antes e após a visitação para o entendimento de um tema específico, ou então, analisar o envolvimento e motivação no processo de organização e apresentação da feira. Dentre os 31 trabalhos analisados, 15 deles tinham o enfoque no estudante, dos outros 16 trabalhos, seis deles o foco não era somente no estudante, mas também no professor e no evento simultaneamente.

\subsubsection{Foco centrado nos professores}

Neste caso, os trabalhos tinham o enfoque principal da pesquisa na figura docente: a concepção do professor sobre determinado tema - espaços não formais e/ou divulgação científica, o papel da feira e/ou procedimentos metodológicos e avaliativos, compreender a participação e permanência dos docentes na organização de uma feira por meio de uma linha psicanalítica e também a feira como ambiente formativo e analisando as relações entre os professores e estudantes e de que forma 0 evento pode contribuir na formação desses sujeitos. Dos 31 trabalhos apresentados nos eventos, referentes às feiras de ciências, quatro deles tinham o enfoque somente no professor. Dos outros 27 trabalhos, em seis deles o foco não era somente no professor, mas também no estudante e no evento simultaneamente.

\subsubsection{Foco centrado nos eventos}

Neste caso, os trabalhos tinham o enfoque principal da pesquisa na análise ou observação do evento em si, neste caso, as feiras: análise de eventos anteriores e/ou etapas do seu desenvolvimento, envolvimento com o público e/ou impacto na comunidade, estudos relacionados a aplicação ou análise 
de alguma teoria envolvendo o público da feira e/ou etapas, com vistas a aplicação de uma metodologia específica. Dos 31 trabalhos apresentados, referentes às feiras de ciências, quatro deles tinham o enfoque somente no evento, na sua organização e na relação da feira com a sociedade. Dos outros 27 trabalhos, dois deles o foco não era somente no evento, mas também no estudante e no professor simultaneamente.

Percebe-se que na maior parte dos trabalhos, o foco da pesquisa é o estudante em nível escolar (15). Observa-se também, em menor número, focos em professores (4) e também nos eventos em si (4). Além disto, nos trabalhos encontrados localizamos um outro foco, estudantes universitários bolsistas (PIBID) e também alunos de licenciatura em física, onde o enfoque do projeto está a formação inicial docente.

Os dados da tabela 4 revelam que praticamente a metade dos trabalhos volta-se exclusivamente aos estudantes. Centrar um estudo nos estudantes evidencia a importância atribuída à aprendizagem e também a o protagonismo discente em algumas situações. Os trabalhos que focaram no professor trouxeram poucas questões pertinentes ao ensino de ciências e problematizaram também a formação docente. Os trabalhos focados no evento e seus impactos reconhecem a importância de atividades escolares abertas à comunidade como espaços de socialização do conhecimento científico.

\subsection{Nível de ensino nos trabalhos apresentados}

Por fim, buscamos traçar dentre os trabalhos selecionados, o nível do ensino nas pesquisas por meio do público envolvido ou pelo tipo de material analisado. Dessa forma, percebemos que há interesse nas pesquisas tanto pela investigação na educação básica, ensino fundamental e médio, com menor predomínio em outros públicos (ensino superior). Neste contexto, a tabela 5 nos mostra a relação dos níveis de ensino nas pesquisas apresentadas.

Tabela 5 - Trabalhos apresentados separados por nível de ensino das pesquisas.

\begin{tabular}{cc}
\hline Nível de ensino & $\begin{array}{c}\text { Quantidade de } \\
\text { trabalhos }\end{array}$ \\
\hline Ensino básico (fundamental) & 11 \\
\hline Ensino básico (médio) & 9 \\
\hline EJA & 2 \\
\hline Ensino superior & 2 \\
\hline Ensino básico + Ensino médio & 3 \\
\hline Ensino médio + Ensino superior & 1 \\
\hline Ensino básico + Ensino médio + Ensino superior & 1 \\
\hline Outros & 2 \\
\hline Fonte: Elaborado pelo autor &
\end{tabular}

Nota-se que o maior número de trabalhos tinha como alvo o Ensino fundamental, em seguida o Ensino médio, Ensino superior e, por fim, o EJA e o público em geral. Uma hipótese para o baixo número de trabalhos dedicados aos universitários pode ser o fato de que as feiras, de uma forma geral, são eventos voltados aos estudantes da educação básica. 
Porém, no ensino superior, eventos com natureza semelhante são realizados sob outras denominações como os salões de iniciação científica, congressos científicos ou reuniões acadêmicas organizadas por alguns cursos.

Tabela 6 - Relação Nível de ensino das instituições

\begin{tabular}{cc}
\hline Nível de ensino das instituições & Quantidade de instituições \\
\hline Federal & 19 \\
\hline Estadual & 8 \\
\hline Privadas & 4 \\
\hline
\end{tabular}

Fonte: Elaborado pelo autor

Quanto ao nível de ensino das instituições da tabela 6: Das oito instituições estaduais, apenas uma delas refere-se a uma escola de ensino médio, que representa a única instituição de nível básico que apresentou um trabalho em um dos eventos científicos nacionais desta pesquisa. Mostrando assim a relevância e a importância das universidades públicas no nosso país.

Tabela 7 - Relação Nível de ensino das pesquisas (foco)

\begin{tabular}{cc}
\hline Nível de ensino das pesquisas (foco) & Quantidade de trabalhos \\
\hline Básico & 22 \\
\hline Superior & 2 \\
\hline Outros & 2 \\
\hline Todos & 5 \\
\hline
\end{tabular}

Fonte: Elaborado pelo autor

Quanto ao nível de ensino das pesquisas (foco) da tabela 7: O termo "Ensino básico" representa o Ensino Fundamental + Ensino Médio + EJA (Educação de Jovens e Adultos); A categoria "Outros" representa o público em geral, e a categoria "Todos" refere-se aos trabalhos que possuem os focos de pesquisa como sendo: Básico + Superior.

A partir das tabelas 6 e 7, que mostra a relação entre o nível de ensino das instituições e o nível de ensino das pesquisas dos trabalhos apresentados nos eventos científicos nacionais, é possível notar que a maioria do conteúdo é produzido por instituições públicas e direcionado aos estudantes de nível básico, uma vez que as feiras de ciências são ambientes favoráveis para a formação dos participantes, para a iniciação científica, bem como para a socialização dos conhecimentos científicos.

\section{CONCLUSÕES}

Partindo do pressuposto que feiras e mostras cientificas são eventos que possibilitam o ensino e a aprendizagem sobre ciências em um contexto ativo que provoca os estudantes a refletirem sobre as ciências no dia-a-dia e em situações concretas, além de viabilizarem que a comunidade externa à escola/instituição tenha acesso ao conhecimento cientifico, o presente trabalho teve como objetivo identificar e classificar estudos científicos que problematizam feiras e mostras cientificas. Tomou-se como fonte de dados seis edições de três eventos científicos nacionais: ENPEC (2017 e 2019), SNEF (2017 e 2019) e EPEF (2016 e 2018). 
A partir dos dados obtidos, nota-se que dentre o universo de trabalhos apresentados nas edições analisadas, apenas $1 \%$ dedicam-se à problematização das feiras e mostras cientificas. Um olhar mais minucioso para estas produções revela que a produção cientifica sobre feiras e mostras distribui-se de maneira desigual pelas regiões do país. Entendemos que este fenômeno não se restringe à temática analisada, posto que há muito mais programas de pós-graduação na região sudeste, impactando a produção cientifica desta região. Outro ponto que se evidencia é o vínculo dos pesquisadores que produziram estes trabalhos, o qual prevalecem as instituições públicas. Novamente devemos considerar que os programas de pós-graduação são oferecidos majoritariamente por universidades públicas (cerca de $80 \%$ ).

Quando analisamos os trabalhos de maneira mais específica, nota-se que há três enfoques predominantes: estudantes, professor e comunidade externa. Em alguns trabalhos há a prevalência de apenas um destes sujeitos e em outros eles se combinam em trabalhos que discutem de maneira mais difusa as feiras e mostras cientificas.

A maior parte dos trabalhos volta-se aos estudantes (48\%). Adotar estudantes como sujeito central de um estudo revela a preocupação com a aprendizagem e o protagonismo discente. Feiras e mostras científicas são oportunidades para que o conhecimento e os conceitos científicos traduzam-se em ações concretas que instigam os estudantes a problematizarem a realidade e buscarem respostas aos problemas levantados. Cerca de $13 \%$ dos trabalhos tomaram como sujeitos os professores, problematizando o papel docente neste tipo de atividade e o caráter formativo que feiras e mostras cientificas podem ter, são experiências que contribuem para o desenvolvimento profissional do docente. Já trabalhos que adotam como perspectiva o evento e o envolvimento da comunidade externa discutem a organização e os impactos do evento somam $13 \%$. Dos $26 \%$ dos trabalhos restantes, 6.4\% referem-se aos estudantes universitários bolsistas (PIBID) e também aos alunos de licenciatura em física, onde o enfoque do projeto está a formação inicial docente. Alguns trabalhos utilizaram mais de um foco de pesquisa, neste caso, correspondendo aos $19.6 \%$ faltantes.

Diante da relevância pedagógica de feiras e mostras cientificas, entendemos que ainda temos uma produção pequena de trabalhos acadêmicos que problematizam o tema. Acreditamos que olhar para feiras e mostras cientificas em sua multidimensionalidade e focar seus diferentes protagonistas, pode contribuir para o ensino e a aprendizagem em ciências pois implica na possibilidade de despertar a curiosidade cientifica nos estudantes, encorajá-los a ler o mundo pelo viés da ciência, identificar problemas e ao mesmo tempo ajudá-los a buscar possíveis respostas. Estudantes e professores posicionam-se de maneira crítica e investigativa ante uma realidade e juntos conseguem apresentar esta realidade sob outras lentes, lentes das ciências. As feiras e mostras são o fechamento deste processo de ensino e aprendizagens conjuntas, são o ápice de meses de trabalho e trazem em si todo o espírito da ciência. Por fim, destacamos que feiras e mostras cientificas têm ainda outro grande mérito que justifica sua relevância como tema de pesquisas, são espaços de democratização do saber, na medida em que a escola/instituição abre suas portas para a comunidade externa e compartilha conhecimentos que são patrimônios da humanidade e dependem de processos educativos para serem usufruídos por todos. 


\section{REFERÊNCIAS}

ARAÚJO, C. A. A. (2006). Bibliometria: evolução histórica e questões atuais. Em Questão, 12(1). http://doi.org/10.19132/1808-5245121.

BRASIL. Diretrizes Curriculares Nacionais da Educação Básica. Ministério da Educação.Secretária de Educação Básica. Diretoria de Currículos e Educação Integral - Brasília: MEC, SEB, DICEI, 2013.

BRASIL. Base Nacional Comum Curricular. 3. versão. Brasília: MEC, 2017. Disponível em: http://portal.mec.gov.br/index.php?option=com_docman\&view=download\&alias=79601-anexotexto-bncc-reexportado-pdf-2\&category_slug=dezembro-2017-pdf\&Itemid=30192. Acesso em: 02 fev. 2021.

Brazilian Journal of Marketing - BJM Revista Brasileira de Marketing - ReMark Vol. 15, N. 2. Abril/Junho. 2016

COSTA, A. B., \& ZOLTOWSKI, A. P. C. (2014). Como escrever um artigo de revisão sistemática. In S. Koller, M. C. P. P. Couto, \& J. Van Hohendorff (Eds), Manual de produção científica (pp. 55-70). Porto Alegre: Penso.

CWTS, 2020. Centre for Science and Tecnhnology Studies, Lelden University, The Netherlands. Disponível em: < https://www.leidenranking.com/ranking/2020/list>. Acesso em: 12 mar. 2021

DE NEGRI, Fernanda; HERNANDEZ, Luis Carlos; ALVES, Priscila Mello. Fé no conhecimento: Como a humanidade enxerga a ciência e a tecnologia? IPEA - Centro de Pesquisa em Ciência, Tecnologia e Sociedade, 2019. Disponível em https://www.ipea.gov.br/cts/pt/central-deconteudo/artigos/artigos/94-fe-no-conhecimento. Acesso em 13.mar.2021

ECHER, I. C. A revisão de literatura na construção do trabalho científico. Revista Gaúcha Enfermagem, Porto Alegre, v. 22, n. 2, p. 5-20, 2001. Disponível em: <http://seer.ufrgs.br/RevistaGauchadeEnfermagem/article/view/ 4365/2324>. Acesso em: 02 fev. 2021.

ENPEC, 2019. XII Encontro Nacional de Pesquisa em Educação em Ciências. Natal - RN. Disponível em: <http://www.abrapecnet.org.br/enpec/xii-enpec>. Acesso em: 02 fev. 2021.

ENPEC, 2017. XI Encontro Nacional de Pesquisa em Educação em Ciências. Florianópolis SC. Disponível em: <http://www.abrapecnet.org.br/enpec/xi-enpec/anais/index.htm>. Acesso em: 02 fev. 2021.

EPEF, 2016. XVI Encontro de Pesquisa e Ensino de Física. Natal - RN. Disponível em: <http://sbfisica.org.br/ fisica2016/>. Acesso em: 02 fev. 2021.

EPEF, 2018. XVII Encontro de Pesquisa e Ensino de Física. Campos do Jordão - SP. Disponível em: <http://www.sbfisica.org.br/ epef/xvii/index.php/pt/index.html>. Acesso em: 02 fev. 2021.

GONÇALVES, T. V. O. Feiras de Ciências e Formação de Professores. In: In: PAVÃO, A.C.; FREITAS, D. (Org.). Quanta ciência há no Ensino de Ciências? São Carlos: EDUFSCAR, 2011.p. 207-215.

MANCUSO, R; LEITE FILHO, I. Feiras de Ciências no Brasil: uma trajetória de quatro décadas. In: BRASIL. Ministério da Educação. Secretaria de Educação Básica. Programa Nacional de Apoio às Feiras de Ciências da Educação Básica Fenaceb. Brasília, DF, 2006. p. 11-43. 
NEVES, S. R. G.; GONÇALVES, T. V. O. Feiras de Ciências. Cad. Cat. Ens. Fís. Florianópolis, v.6, n. 3, p. 241-247, 1989.

SACRISTÁN, J.G. Tendências investigativas na formação de professores. In PIMENTA, Selma Garrido. Professor reflexivo: construindo uma crítica. In PIMENTA, S. G.; GHEDIN, E.(orgs) Professor reflexivo no Brasil: gênese e crítica de um conceito. São Paulo: Cortez, 2006

SNEF, 2017. XXII Simpósio Nacional de Ensino de Física. São Carlos - SP. Disponível em: <http://www.sbfisica.org.br/ snef/xxii >. Acesso em 02 fev. 2021.

SNEF, 2019. XXIII Simpósio Nacional de Ensino de Física. Salvador - BA. Disponível em: <http://www.sbfisica.org.br/ snef/xxiii>. Acesso em 02 fev. 2021.

Submissão: 08/08/2021

Aceito: 18/08/2021 